\title{
PENGARUH PELATIHAN DAN KOMPENSASI TERHADAP KINERJA KARYAWAN CV MURNI RASA BOGOR
}

\author{
Ading Sunarto \\ Fakultas Ekonomi, Universitas Pamulang \\ Email: dosen02153@unpam.ac.id
}

\begin{abstract}
Purpose. The purpose of this study was to determine the effect of job training and compensation on employee performance at CV. Murni Rasa Bogor both partially and simultaneously.
\end{abstract}

Methods. The method used is an quantiitative method. The sampling technique used was saturated sampling using a sample of 47 respondents. Data analysis uses validity test, reliability test, classic assumption test, regression analysis, correlation coefficient analysis, coefficient of determination analysis and hypothesis testing.

Findings. The results of this study are the leadership style has a significant effect on job training with a regression equation $Y=13,268+0,692 X 1$, the correlation coefficient of 0.615 means that the two variables have a strong relationship with a coefficient of determination of $36,5 \%$ and the hypothesis test obtained t count $>t$ table or $(5,233>2,021)$. Compensation has a significant effect on employee performance with a regression equation $Y=6,625+0.468 X 2$. The correlation coefficient value is 0.606 , meaning that the two have a strong relationship with a coefficient of determination of $35.3 \%$ and the hypothesis test is obtained by $t$ count $t$ table or (5.109> 2.021). Leadership style and motivation simultaneously have a significant effect on employee performance with a regression equation $Y=6.625+0.468 X 1+0.382 X 2$. Correlation coefficient values obtained at 0.814 means that the independent variable with the dependent variable has a strong relationship with a coefficient of determination of 49.3\% while the remaining $50.7 \%$ is influenced by other factors. Hypothesis testing obtained $F$ value> $F$ table or $(21.728>3.230)$ thus Ho is rejected and H3 is accepted. This means that there is a significant simultaneous effect between Job training and Compensation on employee performance at CV Murni Rasa Bogor.

Implication. Organizations need to pay more attention to a good training system to be able to improve the performance of their employees, organizations also need to give more compensation to their employees to motivate their employees to do a job.

Keywords. Job Training, Compensation and Employee Performance

\begin{abstract}
ABSTRAK
Tujuan. Tujuan penelitian ini adalah untuk mengetahui pengaruh pelatihan kerja dan kompensasi terhadap kinerja karyawan pada CV Murni Rasa Bogor baik secara parsial maupun secara simultan.

Metode. Metode yang digunakan adalah metode Kuantitatif. Teknik sampling yang digunakan adalah sampling jenuh menggunakan dengan sampel sebanyak 47 responden. Analisis data menggunakan uji validitas, uji reliabilitas, uji asumsi klasik, analisis regresi, analisis koefisien korelasi, analisis koefisien determinasi dan uji hipotesis.
\end{abstract}


Hasil. Hasil penelitian ini adalah Pelatihan kerja berpengaruh signifikan terhadap kinerja karyawan dengan persamaan regresi $Y=13,268+0,692 X 1$, nilai koefisien korelasi sebesar 0,615 artinya kedua variabel memiliki hubungan yang kuat dengan koefisien determinasi sebesar 36,5\% dan uji hipotesis diperoleh $t$ hitung $>t$ tabel atau $(5,233>2,021)$. Kompensasi berpengaruh signifikan terhadap kinerja karyawan dengan persamaan regresi $\mathrm{Y}=18,121+0,582 \mathrm{X} 2$ nilai koefisien korelasi sebesar 0,606 artinya kedua memiliki hubungan yang kuat dengan koefisien determinasi sebesar 35,3\% dan uji hipotesis diperoleh $\mathrm{t}$ hitung $>\mathrm{t}$ tabel atau $(5,109>2,021)$. Pelatihan kerja dan Kompensasi secara simultan berpengaruh signifikan terhadap kinerja karyawan dengan persamaan regresi $Y=$ $6,625+0,468 \mathrm{X} 1+0,382 \mathrm{X} 2$. Nilai koefisien korelasi diperoleh sebesar 0,814 artinya variabel bebas dengan variabel terikat memiliki hubungan yang kuat dengan koefisien determinasi sebesar 49,3\% sedangkan sisanya sebesar 50,3\% dipengaruhi faktor lain. Uji hipotesis diperoleh nilai $\mathrm{F}$ hitung $>\mathrm{F}$ tabel atau $(21,728>3,230)$ dengan demikian Ho ditolak dan $\mathrm{H} 3$ diterima. Artinya terdapat pengaruh yang signifikan secara simultan antara Pelatihan kerja dan Kompensasi terhadap kinerja karyawan pada CV Murni Rasa Bogor.

Implikasi. Organisasi perlu lebih memperhatikan sistem pelatihan yang baik untuk dapat meningkatkan kinerja karyawannya, organisasi juga perlu lebih memberikan kompensasi karyawan-karyawan nya untuk lebih memotivasi kerja karyawannya dalam melakukan suatu pekerjaan.

\section{Kata Kunci. Pelatihan Kerja, Kompensasi dan Kinerja Karyawan}

\section{Pendahuluan}

Perusahaan adalah suatu lembaga yang dijalankan untuk menyediakan barang dan jasa agar dapat melayani permintaan konsumen akan kebutuhan mereka. Dalam melaksanakan proses produksinya, suatu perusahaan membutuhkan faktor-faktor produksi yang dapat menunjang tercapainya tujuan perusahaan. Faktor-faktor tersebut adalah bahan baku, modal, manusia dan skill.

Terkhusus pada faktor manusia, karena pada dasarnya sumber daya manusia adalah faktor yang paling penting menentukan dalam mencapai tujuan perusahaan. Karena sumber daya manusia termasuk unsur dari kekuatan daya saing bangsa, untuk itu sumber daya manusia dituntut menjadi unggul dan profesional dalam kerjaannya demi kemajuan dan pencapaian tujuan perusahaan di Indonesia khususnya agar bisa bersaing dalam era globalisasi ini. Untuk mencapai tujuan tersebut perusahaan dapat memanfaatkan segala kemampuan dan kesempatan yang ada semaksimal mungkin serta memperkecil hambatan-hambatan dan kelemahan-kelemahan yang dihadapinya.

Apa jadinya suatu perusahaan menerima karyawan tanpa mengadakan pelatihan. Bisa jadi karyawan tersebut bingung entah bagimana untuk mengawali pekerjaannya. Pelatihan sangat dibutuhkan untuk karyawan baru ataupun yang sudah lama agar lebih maksimal dalam melakukan pekerjaannya. Maka dari itu setiap perusahaan menghendaki agar setiap tenaga kerja dapat bekerja secara efektif dan efisien. Rendahnya kualitas tenaga kerja sangat berpengaruh terhadap pengembangan dan peningkatan produksi dalam berbagai bidang. Hal tersebut dikarenakan tenaga kerja memegang peranan penting dalam usaha untuk mencapai tujuan perusahaan.Suatu perusahaan yang mempunyai tujuan untuk mengembangkan dan menghasilkan laba, maka kinerja karyawan sangat penting sebagai alat ukur keberhasilan dalam menjalankan usaha. Keberhasilan suatu perusahaan tercermin dari hasil kerja masing-masing individu dalam perusahaan, hasil kerja tersebut akan berpengaruh pada hasil kerja yang menyeluruh.

CV Murni Rasa Bogor adalah perusahaan yang bergerak di bidang Food Court. Di Indonesia perusahaan makanan dan minuman dapat berkembang pesat,hal ini terlihat dari jumlah perusahaan yang terdaftar di bursa efek Indonesia dari periode ke periode semakin banyak, walaupun ada beberapa perusahaan yang pernah mengalami defisiensi modal untuk sementara karena imbas dari krisis ekonomi. Tetapi tidak menutup kemungkinan perusahaan 
ini sangat dibutuhkan masyarakat sehingga prospeknya sangat menguntungkan di masa sekarang maupun masa yang akan datang. Alasan pemilihan sektor food Court adalah karena saham tersebut adalah saham-saham paling tahan krisis ekonomi di banding sektor lain karena dalam kondisi krisis atau tidak, sebagian produk makanan dan minuman tetap di butiuhkan. Di lembaga inilah aktivitas para pegawai diharapkan mampu berperan dalam mewujudkan suatu tujuan perusahaan. Di instansi atau lembaga inilah semestinya para pegawai CV Murni Rasa Bogor bekerja secara optimal demi kemajuan kualitas kinerja dan mencapai target perusahaan yang telah ditentukan disetiap bulannya.

Berdasarkan survey pendahuluan yang dilakukan di CV Murni Rasa Bogor ternyata semua yang di jalankan di dalam operasional perusahaan sudah memenuhi standar kriteria pelayanan yang di harapkan oleh para pelanggan, mulai dari penyajian makanan sampai tata cara pelayan menyajikan makanan dan minuman yang di hidangkan kepada para pelanggan. Kemudian kedisiplina dari semua karyawan yang rajin dan taat terhadap peraturan perusahaan menjadi nilai tambahan dari perusahaan kepada para karyawan sehingga itu menjadi motivasi tersendiri bagi para karyawan sehingga bekerja dengan loyal kepada perusahaan.

Berkaitan dengan hal tersebut, maka setiap organisasi maupun perusahaan akan selalu berusaha untuk meningkatkan kinerja karyawannya, dengan harapan apa yang menjadi tujuan organisasi akan tercapai. Berbagai cara akan di tempuh dalam peningkatan kinerja karyawan. Oleh sebab itu penelitian ini dilakukan untuk meneliti lebih lanjut tentang "Pengaruh Pelatihan Kerja dan Kompensasi Terhadap Kinerja Karyawan Pada CV Murni Rasa Bogor".

\section{Kajian Pustaka dan Hipotesis}

Pelatihan Kerja. Pelatihan Kerja adalah setiap usaha memperbaiki prestasi kerja pada suatu pekerjaan tertentu yang menjadi tanggung jawabnya. Menurut Wilson Bangun (2016:201) "Pelatihan Kerja adalah merupakan proses untuk mempertahankan atau memperbaiki keterampilan karyawan untuk menghasilkan pekerjaan yang efektif".

$\mathbf{H}_{\mathbf{1}}$. Pelatihan Kerja berpengaruh signifikan terhadap kinerja karyawan

Kompensasi. Kompensasi merupakan salah satu cara yang di lakukan untuk meningkatkan kepuasan kerja karyawan dan kinerja karyawan. Kompensasi merupakan suatu hal yang penting bagi karyawan sebagai suatu individu, karena besarnya kompensasi yang di berikan merupakan suatu ukuran keberhasilan bagi individu tersebut. Bila pemberian kompensasi diberikan secara tepat maka akan mempengaruhi perilaku para karyawan untuk mencapai tujuan-tujuan organisasi. Menurut Malayu S.P Hasibuan (2016:118) "kompensasi adalah semua pendapatan yang berbentuk uang atau barang langsung maupun tidak langsung yang di terima karyawan sebagai imbalan atas jasa yang telah di berikan kepada perusahaan".

$\mathbf{H}_{2}$. Kompensasi berpengaruh signifikan terhadap produktivitas karyawan

Kinerja. Kinerja adalah hasil yang dicapai seseorang atau sekelompok orang dalam organisasi dengan wewenang dan tanggung jawab masing-masing dalam rangka mencapai tujuan organisasi bersangkutan secara legal, tidak melanggar hokum dan sesuai dengan moral dan etika,kinerja juga dapat di artikan sebagai suatu kemampuan kerja, prestasi yang di perhatikan atau yang di capai dalam melaksanakan suatu fungsi pekerjaan dalam suatu periode tertentu. Menurut A.A. Anwar Prabu Mangkunegara (2018:9) bahwa "kinerja karyawan (prestasi kerja) adalah hasil kerja secara kualitas dan kuantitas yang di capai oleh seorang karyawan dalam melaksanakan tugasnya sesuai dengan tanggung jawab yang di berikan kepadanya".

$\mathbf{H}_{3}$. Pelatihan Kerja dan Kompensasi berpengaruh signifikan terhadap kinerja karyawan 


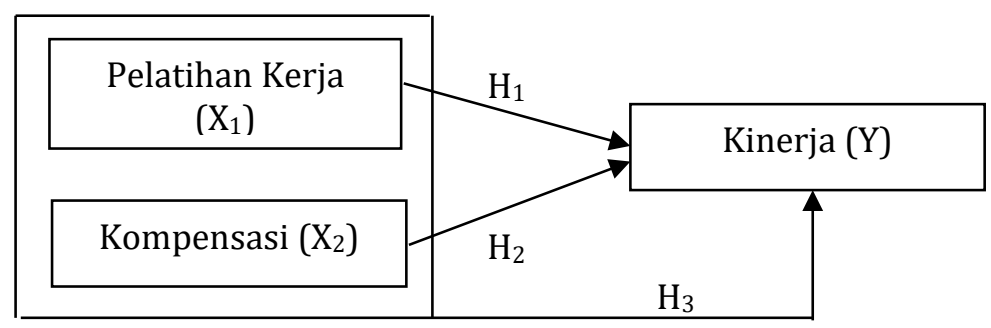

Gambar 1. Model Penelitian

\section{Metode Penelitian}

Jenis penelitian ini adalah asosiatif, menurut Sugiyono (2012:44) yaitu "Penelitian yang bertujuan untuk mengetahui pengaruh atau hubungan antara dua variabel atau lebih". Dengan demikian penelitian asosiatif ini dapat dibangun suatu teori yang berfungsi untuk menjelaskan, meramalkan dan mengontrol suatu gejala. Populasi dalam penelitian ini adalah pegawai CV Murni Rasa yang berjumlah 47 orang. Sampel dalam penelitian ini adalah berjumlah 47 orang pegawai di CV Murni Rasa Bogor. Dengan demikian teknik pengambilan sampel yang digunakan dalam penelitian ini adalah teknik sampling jenuh.Sampling jenuh adalah teknik penentuan sampel bila semua anggota populasi digunakan sebagai sampel (Sugiyono, 2017:124).

\section{Uji Instrumen Penelitian}

Dalam suatu penelitian, data mempunyai kedudukan yang sangat penting. Hal ini dikarenakan data merupakan penggambaran variabel yang diteliti dan berfungsi sebagai alat pembuktian hipotesis. Valid atau tidaknya data sangat menentukan kualitas dari data tersebut. Hal ini tergantung instrumen yang digunakan apakah sudah memenuhi asas validitas dan reliabilitas. Adapun dalam pengujian instrumen ini digunakan 2 (dua) pengujian yaitu validitas dan reliabilitas.

\section{Uji Asumsi Klasik}

Uji asumsi klasik digunakan untuk mengetahui ketepatan sebuah data. Menurut Santoso (2015:342) berpendapat "Sebuah model regresi akan digunakan untuk melakukan peramalan sebuah model yang baik adalah model dengan kesalahan peramalan yang seminimal mungkin. Karena itu, sebuah model sebelum digunakan seharusnya memenuhi beberapa asumsi, yang biasa disebut asumsi klasik". Dalam penelitian ini uji asumsi klasik yang digunakan: Uji Normalitas, Uji Multikolinearitas, Uji Autokorelasi, dan Uji Heterokedastisitas.

\section{Analisis Kuantitatif}

Analisis kuantitatif adalah penelitian untuk menilai kondisi dari nilai pengaruh, dan signifikansi pengaruh tersebut. Dalam penelitian ini analisis kuantitatif yang digunakan: Analisis Regresi Linier Sederhana, Linier Berganda, Analisis Koefisien Korelasi, Analisis Koefisien Determinasi, Pengujian Hipotesis.

\section{Hasil Penelitian dan Pembahasan Uji Validitas Instrumen}

Tabel 1. Hasil Uji Validitas Variabel Pelatihan Kerja $\left(\mathrm{X}_{1}\right)$

\begin{tabular}{|c|c|c|c|}
\hline Pernyataan & r hitung & r tabel & Hasil Uji \\
\hline Pernyataan 1 & 0.668 & 0.288 & Valid \\
\hline Pernyataan 2 & 0.626 & 0.288 & Valid \\
\hline Pernyataan 3 & 0.710 & 0.288 & Valid \\
\hline Pernyataan 4 & 0.651 & 0.288 & Valid \\
\hline
\end{tabular}




\begin{tabular}{|c|c|c|c|}
\hline Pernyataan & r hitung & r tabel & Hasil Uji \\
\hline Pernyataan 5 & 0.684 & 0.288 & Valid \\
\hline Pernyataan 6 & 0.650 & 0.288 & Valid \\
\hline Pernyataan 7 & 0.598 & 0.288 & Valid \\
\hline Pernyataan 8 & 0.755 & 0.288 & Valid \\
\hline Pernyataan 9 & 0.708 & 0.288 & Valid \\
\hline Pernyataan 10 & 0.673 & 0.288 & Valid \\
\hline
\end{tabular}

Sumber : Data diolah (2021)

Tabel 2. Hasil Uji Validitas Variabel Kompensasi $\left(\mathrm{X}_{2}\right)$

\begin{tabular}{|c|c|c|c|}
\hline Pernyataan & r hitung & r tabel & Hasil Uji \\
\hline Pernyataan 1 & 0.566 & 0.288 & Valid \\
\hline Pernyataan 2 & 0.757 & 0.288 & Valid \\
\hline Pernyataan 3 & 0.775 & 0.288 & Valid \\
\hline Pernyataan 4 & 0.811 & 0.288 & Valid \\
\hline Pernyataan 5 & 0.853 & 0.288 & Valid \\
\hline Pernyataan 6 & 0.793 & 0.288 & Valid \\
\hline Pernyataan 7 & 0.663 & 0.288 & Valid \\
\hline Pernyataan 8 & 0.604 & 0.288 & Valid \\
\hline Pernyataan 9 & 0.718 & 0.288 & Valid \\
\hline Pernyataan 10 & 0.418 & 0.288 & Valid \\
\hline
\end{tabular}

Sumber : Data diolah (2021)

Tabel 3. Hasil Uji Validitas Variabel Kinerja (Y)

\begin{tabular}{|c|c|c|c|}
\hline Pernyataan Y & r hitung & r tabel & Hasil Uji \\
\hline Pernyataan 1 & 0.627 & 0.288 & Valid \\
\hline Pernyataan 2 & 0.748 & 0.288 & Valid \\
\hline Pernyataan 3 & 0.705 & 0.288 & Valid \\
\hline Pernyataan 4 & 0.743 & 0.288 & Valid \\
\hline Pernyataan 5 & 0.712 & 0.288 & Valid \\
\hline Pernyataan 6 & 0.755 & 0.288 & Valid \\
\hline Pernyataan 7 & 0.717 & 0.288 & Valid \\
\hline Pernyataan 8 & 0.874 & 0.288 & Valid \\
\hline Pernyataan 9 & 0.775 & 0.288 & Valid \\
\hline Pernyataan 10 & 0.787 & 0.288 & Valid \\
\hline
\end{tabular}

Sumber : Data diolah (2021)

Berdasarkan data tabel di atas, variabel $X_{1}, X_{2}$ dan $Y$ diperoleh nilai $r$ hitung $>r$ tabel (0.288), dengan demikian maka semua item kuesioner dinyatakan valid. Untuk itu kuesioner yang digunakan layak untuk diolah sebagai data penelitian.

\section{Uji Reliabilitas Instrumen}

Tabel 4. Hasil Uji Reliabilitas Variabel Independen dan Dependen

\begin{tabular}{|c|c|c|c|}
\hline Variabel & Cronbatch Alpha & $\begin{array}{c}\text { Standar Cronbatch } \\
\text { Alpha }\end{array}$ & Keputusan \\
\hline Pelatihan Kerja (X1) & 0,863 & 0,600 & Reliabel \\
\hline Kompensasi (X2) & 0,877 & 0,600 & Reliabel \\
\hline Kinerja (Y) & 0,909 & 0,600 & Reliabel \\
\hline
\end{tabular}

Sumber : Data diolah (2021) 
Berdasarkan hasil pengujian pada tabel di atas, menunjukkan bahwa variabel pelatihan kerja $\left(\mathrm{X}_{1}\right)$, kompensasi $\left(\mathrm{X}_{2}\right)$ dan kinerja $(\mathrm{Y})$ dinyatakan reliabel, hal itu dibuktikan dengan masing-masing variabel memiliki nilai Chronbath Alpha lebih besar dari 0,600.

\section{Pengujian Asumsi Klasik (Uji Prasyarat Data)}

\section{Uji Normalitas}

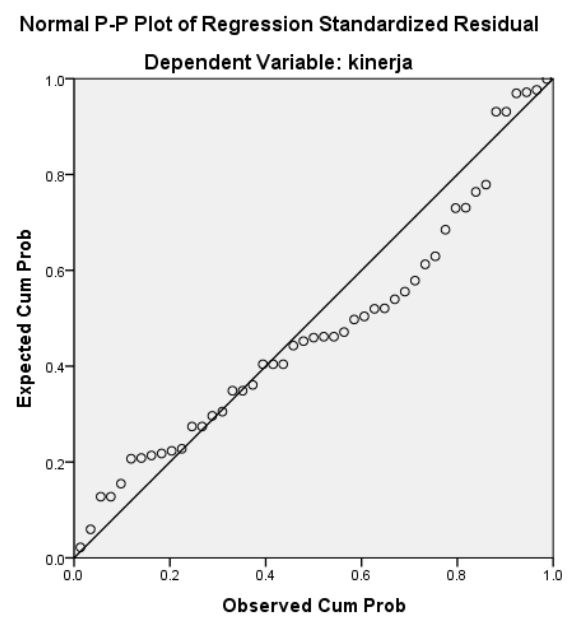

Sumber : Hasil Pengolahan Data SPSS, tahun 2021

\section{Gambar 2. Uji Normalitas P-P Plot}

Dari gambar grafik di atas, memperlihatkan titik-titik jawaban responden mengikuti arah garis diagonal, dengan demikian data memenuhi unsur normalitas.

\section{Uji Multikolinearitas}

Tabel 5. Hasil Pengujian Multikolinearitas Dengan Collinearity Statistic Kinerja Karyawan Sebagai Variabel Dependen

\begin{tabular}{|c|c|c|}
\hline \multirow{2}{*}{ Variabel } & \multicolumn{2}{|c|}{ Colinerity Statistics } \\
\cline { 2 - 3 } & Tolerance & VIF \\
\hline Rekruitmen (X1) & 0.667 & 1.334 \\
\hline Seleksi (X2) & 0.667 & 1.334 \\
\hline
\end{tabular}

Sumber : data output yang diolah, 2021

Berdasarkan hasil pengujian multikolinieritas pada tabel di atas diperoleh nilai tolerance masing-masing variabel bebas yaitu pelatihan kerja sebesar 0,750 dan kompensasi sebesar 0,750, dimana kedua nilai tersebut kurang dari 1, dan nilai Variance Inflation Factor (VIF) variabel pelatihan kerja sebesar 1,334 serta kompensasi sebesar 1,334 dimana nilai tersebut kurang dari 10. Dengan demikian model regresi ini tidak ada multikolinearitas.

\section{Uji Autokorelasi}

Tabel 6. Uji Durbin-Watson

\begin{tabular}{|c|c|c|c|c|c|}
\hline \multicolumn{6}{|c|}{ Model Summaryb } \\
\hline Model & $\mathrm{R}$ & R Square & $\begin{array}{l}\text { Adjusted R } \\
\text { Square }\end{array}$ & $\begin{array}{l}\text { Std. Error of } \\
\text { the Estimate }\end{array}$ & $\begin{array}{l}\text { Durbin- } \\
\text { Watson }\end{array}$ \\
\hline 1 & $.705^{\mathrm{a}}$ & 497 & .474 & 2.61489 & 2.084 \\
\hline \multicolumn{6}{|c|}{ a. Predictors: (Constant), Kompensasi (X2), Pelatihan Kerja (X1) } \\
\hline b. Depe & ent Va & iable: Kiner & $(\mathrm{Y})$ & & \\
\hline
\end{tabular}


Berdasarkan hasil pengujian pada tabel di atas, model regresi ini tidak ada autokorelasi, hal ini dibuktikan dengan nilai Durbin-Watson sebesar 2.084 yang berada diantara interval $1.550-2.460$.

\section{Uji Heteroskedastisitas}

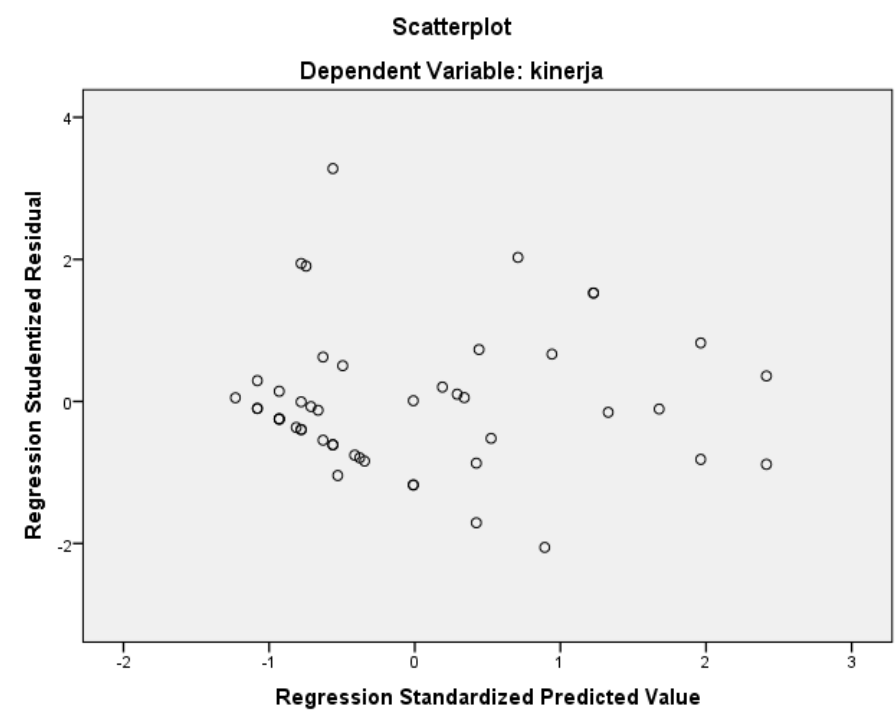

Sumber : data output yang diolah, 2021

\section{Gambar 3 Uji Heteroskedastisitas}

Pada gambar diatas, dapat bisa dilihat bahwa titik - titik pada grafik scatterplot tidak mempunyai pol ayang jelas dan penyebaran nya tidak teratur diatas dan dibawah angka 0 pada sumbu Y, maka dapat disimpulkan bahwa tidak terjadi masalah heteroskedastisitas.

\section{Analisis Kuantitatif}

\section{Regresi Linier Berganda}

Tabel 7. Hasil Pengujian Regresi Berganda Variabel Pelatihan Kerja ( $\left.\mathrm{X}_{1}\right)$ dan Kompensasi $\left(\mathrm{X}_{2}\right)$ Terhadap Kinerja $(\mathrm{Y})$

\begin{tabular}{|c|c|c|c|c|c|c|}
\hline \multicolumn{7}{|c|}{ Coefficients $^{a}$} \\
\hline & \multirow[t]{2}{*}{ Model } & \multicolumn{2}{|c|}{$\begin{array}{l}\text { Unstandardized } \\
\text { Coefficients }\end{array}$} & \multirow{3}{*}{$\begin{array}{c}\begin{array}{c}\text { Standardized } \\
\text { Coefficients }\end{array} \\
\text { Beta } \\
\end{array}$} & \multirow[t]{2}{*}{$\mathrm{t}$} & \multirow[t]{2}{*}{ Sig. } \\
\hline & & $B$ & Std. Error & & & \\
\hline \multirow{3}{*}{1} & (Constant) & 6.625 & 5.574 & & 1.189 & .241 \\
\hline & $\begin{array}{l}\text { Pelatihan } \\
\text { (X1) }\end{array}$ & .468 & .139 & .416 & 3.369 & .002 \\
\hline & Kompensasi (X2) & .382 & .119 & .398 & 3.220 & .002 \\
\hline
\end{tabular}

Sumber : Data diolah (2021)

Berdasarkan hasil analisis perhitungan regresi pada tabel di atas, maka dapat diperoleh persamaan regresi $\mathrm{Y}=6,625+0,468 \mathrm{X}_{1}+0,382 \mathrm{X}_{2}$. Dari persamaan di atas maka dapat disimpulkan sebagai berikut:

1. Nilai konstanta yaitu sebesar 6,625 yang menyatakan bahwa jika nilai dari variabel pelatihan kerja (x1) dan kompensasi (x2) tidak ada atau bernilai $=0$ maka nilai dari variabel kinerja karyawan (Y) adalah 6,625.

2. Nilai dari koefisien regresi dari variabel pelatihan kerja (x1) adalah sebesar 0,468 , maka dapat diartikan jika variabel bebas (independent) lain nilainya tetap dan kompensasi 
mengalami kenaikan 1 poin maka kinerja karyawan nya juga ikut meningkat sebesar 0,468 satuan dan koefisien bernilai positif yang dimana artinya jika pelatihan kerja mengalami peningkatan maka kinerja karyawan juga akan ikut meningkat.

3. Nilai dari koefisien regresi dari variabel kompenasi (x2) adalah 0,382, maka dapat diartikan jika variabel bebas (independent) lain nilainya tetap dan kompensasi mengalami kenaikan 1 poin maka kinerja karyawan juga ikut meningkat sebesar 0,382 satuan dan koefisien bernilai positif yang artinya jika kompensasi mengalami peningkatan maka kinerja karyawan juga akan ikut meningkat.

\section{Analisis Koefisien Determinasi (R Square)}

Tabel 8. Hasil Analisis Koefisien Determinasi Secara Simultan Antara Variabel Pelatihan Kerja $\left(\mathrm{X}_{1}\right)$ dan Kompensasi $\left(\mathrm{X}_{2}\right)$ Terhadap Kinerja $(\mathrm{Y})$

\begin{tabular}{|l|c|c|c|c|}
\hline \multicolumn{5}{|c|}{ Model Summary } \\
\hline Model & $\mathrm{R}$ & $\begin{array}{c}\mathrm{R} \\
\text { Square }\end{array}$ & $\begin{array}{c}\text { Adjusted R } \\
\text { Square }\end{array}$ & $\begin{array}{c}\text { Std. Error of the } \\
\text { Estimate }\end{array}$ \\
\hline 1 & $.705^{\mathrm{a}}$ & .497 & .474 & 2.61489 \\
\hline \multicolumn{4}{|r|}{ a. Predictors: (Constant), Kompensasi (X2), Pelatihan Kerja (X1) } \\
\hline
\end{tabular}

Sumber : Data diolah (2021)

Berdasarkan pada hasil pengujian pada tabel di atas, didapatlah nilai $\mathrm{R}=0,705$ dan koefisien Determinasi (R square) sebesar 0,497. Hal ini menunjukan pengertian bahwa antara variabel pelatihan kerja (X1) dan kompensasi (X2) terhadap kinerja karyawan (Y) mempunyai hubungan yang cukup kuat dengan nilai R 0,705 dan kontribusi kedua variabel bebas R2 sebesar 49,7\% sedangkan sisanya sebesar 50.3\% dipengaruhi oleh variabel lain diluar variabel yang digunakan penelitian ini.

\section{Pengujian Hipotesis}

Tabel 9. Hasil Uji Hipotesis (Uji t) Variabel Pelatihan Kerja $\left(X_{1}\right)$ dan Kompensasi $\left(X_{2}\right)$ Terhadap Kinerja (Y)

\begin{tabular}{|c|c|c|c|c|c|c|}
\hline \multicolumn{7}{|c|}{ Coefficients $^{a}$} \\
\hline & \multirow[t]{2}{*}{ Model } & \multicolumn{2}{|c|}{$\begin{array}{c}\text { Unstandardized } \\
\text { Coefficients }\end{array}$} & \multirow{2}{*}{$\begin{array}{c}\begin{array}{c}\text { Standardized } \\
\text { Coefficients }\end{array} \\
\text { Beta }\end{array}$} & \multirow[t]{2}{*}{$\mathrm{t}$} & \multirow[t]{2}{*}{ Sig. } \\
\hline & & B & Std. Error & & & \\
\hline \multirow{3}{*}{1} & (Constant) & 13.368 & 5.678 & & 2.354 & 0.023 \\
\hline & $\begin{array}{l}\text { Pelatihan Kerja } \\
\text { (X1) }\end{array}$ & .692 & 132 & .615 & 5.233 & .000 \\
\hline & Kompensasi (X2) & .582 & .114 & .606 & 5.109 & .000 \\
\hline
\end{tabular}

Sumber : Data diolah (2021)

Berdasarkan tabel diatas dapat dilihat hasil output data yang telah diolah, dapat dijelaskan tentang pengaruh variabel independen terhadap variabel dependen seperti berikut ini :

1. Pengaruh Pelatihan Kerja (x1) terhadap kinerja karyawan (y) : Berdasarkan output SPSS diatas diketahui nilai thitung variabel pelatihan kerja adalah sebesar 5,233. Karena nilai thitung 5,233 > ttabel 2,021 maka dapat disimpulkan bahwa Ho ditolak dan Ha diterima. hal ini menunjukkan bahwa terdapat pengaruh yang signifikan secara parsial antara Pelatihan Kerja terhadap Kinerja Karyawan pada CV Murni Rasa Bogor.

2. Pengaruh Kompenasi (x2) terhadap kinerja karyawan (y) : Berdasarkan tabel output SPSS diatas diketahui nilai thitung variabel kompenasi (x2) adalah sebesar 5,109. Karena thitung 5,109 > ttabel 2,021. Maka dapat disimpulkan bahwa Ho ditolak dan Ha diterima. hal ini menunjukkan bahwa terdapat pengaruh yang signifikan secara parsial antara Pelatihan Kerja terhadap Kinerja Karyawan pada CV CV Murni Rasa Bogor. 
Tabel 10. Uji F Secara Simultan Antara Pelatihan Kerja $\left(X_{1}\right)$ dan Kompenasi $\left(X_{2}\right)$ Terhadap Kinerja (Y)

\begin{tabular}{|c|c|c|c|c|c|c|}
\hline \multicolumn{7}{|c|}{ ANOVA $^{a}$} \\
\hline & Model & $\begin{array}{c}\text { Sum of } \\
\text { Squares }\end{array}$ & df & $\begin{array}{c}\text { Mean } \\
\text { Square }\end{array}$ & $\mathrm{F}$ & Sig. \\
\hline \multirow{3}{*}{1} & Regression & 297.143 & 2 & 148.572 & 21.728 & $.001^{\mathrm{b}}$ \\
\hline & Residual & 300.857 & 44 & 5.838 & & \\
\hline & Total & 598.000 & 46 & & & \\
\hline \multicolumn{7}{|c|}{ a. Dependent Variable: Kinerja (Y) } \\
\hline
\end{tabular}

Sumber : Data diolah (2021)

Berdasarakan tabel output SPSS di atas, diketahui nilai Fhitung adalah sebesar 21,728. Karena nilai Fhitung 21,728 > Ftabel 3,230, maka sebagaimana dasar pengambilan keputusan dalam uji $\mathrm{F}$ dapat disimpulkan bahwa hipotesis diterima atau dengan kata lain pelatihan kerja (x1) dan kompenasi (x2) secara simultan berpengaruh terhadap kinerja karyawan (y).

\section{Kesimpulan}

Berdasarkan penelitian yang telah dilakukan serta diuraikan oleh penulis pada bab IV mengenai pengaruh pelatihan kerja dan kompensasi terhadap kinerja karyawan CV Murni Rasa Bogor maka dapat disimpulkan sebagai berikut: Pelatihan Kerja pada CV Murni Rasa Bogor baik, hal tersebut dibuktikan dengan hasil uji regresi linier sederhana dengan rumus $\mathrm{Y}=\mathrm{a}+\mathrm{b}_{1} \mathrm{X}_{1}$, dengan hasil $\mathrm{Y}=13,368+0,692 \mathrm{X}_{1}$. Dan berdasarkan hasil uji t antara variabel kompensasi dan kinerja karyawan didapatkan nilai thitung $>$ ttabel $(3,369>2,012)$ menunjukkan bahwa pelatihan kerja berpengaruh terhadap kinerja karyawan.

Kompensasi pada CV Murni Rasa Bogor baik, hal tersebut dibuktikan dengan hasil uji regresi linier sederhana dengan rumus $\mathrm{Y}=\mathrm{a}+\mathrm{b}_{2} \mathrm{X}_{2}$, dengan hasil $\mathrm{Y}=18,121+0,582 \mathrm{X}_{2}$. Dan jika dilihat berdasarkan hasil uji $\mathrm{t}$ antara variabel pelatihan kerja terhadap kinerja karyawan didapatkan nilai thitung > ttabel $(3,220>2,012)$, maka dengan demikian kompensasi berpengaruh terhadap kinerja karyawan.

Terdapat pengaruh secara bersama-sama antara pelatihan kerja dan kompensasi terhadap kinerja pegawai pada CV Murni Rasa Bogor dengan uji regresi linier berganda dengan rumus $Y=a+b_{1} X_{1}+b_{2} X_{2}$, dengan hasil $Y=6,625+0,468 X_{1}+0,382 X_{2}$. Dan hasil uji $F$ dimana nilai Fhitung $>$ Ftabel $(21,728>3,18)$. Dengan nilai koefisien determinasi (R2) yang diperoleh sebesar 0.497. Hal ini menunjukkan bahwa kompensasi dan pelatihan kerja memberikan pengaruh positif terhadap kinerja karyawan sebesar 0,497 atau 49,7\% sedangkan sisanya sebesar 0,503 atau $50,3 \%$ disebabkan oleh faktor lain yang tidak diteliti dalam penelitian ini.

\section{Daftar Pustaka}

AA. Anwar Prabu Mangkunegara, (2018). Manajemen Sumber Daya Manusia Perusahaan, Remaja Rosdakarya, Bandung.

Ading, S. (2020). Pengaruh Gaya Kepemimpinan, Motivasi, Serta Disiplin Kerja Terhadap Kinerja Karyawan (Study di PT Mitsui Leasing Capital Indonesia Abdul Muis-Jakarta Pusat). KREATIF: Jurnal Ilmiah Prodi Manajemen Universitas Pamulang, 8(1), 18-38.

Bangun, Wilson. (2016). “Manajemen Sumber Daya Manusia”. Jakarta: Erlangga.

Hasibuan, Malayu S.P. (2016). Manajemen Sumber Daya Manusia (Edisi revisi cetakan ke tiga belas). Jakarta: PT. Bumi Aksara

Santoso, S. (2015). SPSS20 Pengolahan Data Statistik di Era Informasi, Jakarta, PT. Alex Media Komputindo, Kelompok Gramedia.

Sugiyono. (2012). Metode Penelitian Kuantitatif Kualitatif Dan R\&D. Bandung: PT. Alfabet.

Sugiyono. (2017). Metode Penelitian Kuantitatif, Kualitatif dan R\&D. Bandung: Alfabeta. 
Sunarto, A., \& Aprianda, D. (2021). Pengaruh Rekruitmen Dan Seleksi Terhadap Produktivitas Kerja Guru Pada Yayasan Pondok Indah Don Bosco Jakarta Selatan. Jurnal Arastirma, 1(1), 106-116. Https://Doi.Org/10.32493/Arastirma.V1i1.10067

Sunarto, A., Qurbani, D., \& Virby, S. (2020). Pengaruh Kompetensi, Disiplin Kerja Dan Lingkungan Kerja Terhadap Kinerja Pada PT Anugrah Bersama Sejahtera Depok. JIMF (Jurnal Ilmiah Manajemen Forkamma), 4(1).

Sunarto, A., Tanjung, A. W., \& Ellesia, N. (2020). Teacher Performance Based on The Visionary Leadership Style of School, Competency and Work Discipline (Study at Muhammadiyah Setiabudi Pamulang College).Journal of Research in Business, Economics, and Education, 2(5), 1046-1052.

Sunarto, A. (2020). Kinerja Karyawan Berbasis Kepemimpinan Dan Motivasi Pada PT. Duta Jaya Putra Persada Mining. JENIUS (Jurnal Ilmiah Manajemen Sumber Daya Manusia), 3(3), 246-257.

Sunarto, A. (2020). Pengembangan Sumber Daya Manusia dengan Berbasis Inovasi Untuk Menghadapi Revolusi Industri 4.0. Jurnal Ilmiah MEA (Manajemen, Ekonomi, \& Akuntansi), 4(2), 397-407.

Sunarto, A. (2020). Kinerja Karyawan Berbasis Kepemimpinan Dan Motivasi Pada PT. Duta Jaya Putra Persada Mining. JENIUS (Jurnal Ilmiah Manajemen Sumber Daya Manusia), 3(3), 246-257.

Sunarto, A. (2019). Analisis Kinerja Karyawan Pada PT. Bank Mandiri Cluster Cilegon I. SCIENTIFIC JOURNAL OF REFLECTION: Economic, Accounting, Management and Business, 2(3), 241-250.

Sunarto, A. (2020). Kinerja Pegawai Berbasis Kepemimpinan Dan Lingkungan Kerja Pada PT Victory Chingluh Indonesia Divisi Quality. Kreatif: Jurnal Ilmiah Prodi Manajemen Universitas Pamulang, 8(2), 92-101.

Sunarto, A. (2021). Pengaruh Komunikasi Dan Gaya Kepemimpinan Terhadap Kinerja Pegawai Pada PT. Visionet Data Internasional Cabang Karawaci. Jurnal Semarak, 4(2), 105-118.

Sunarto, A. (2021). Kinerja Pegawai Berbasis Disiplin Dan Lingkungan Kerja (Studi Pada Kantor Kecamatan Pondok Aren Kota Tangerang Selatan). Jurnal Visionida, 7(1), 1-13.

Sunarto, A. (2019). Hubungan Stress Kerja Dan Produktivitas Kerja Karyawan Pada PT. BANK Mandiri Cluster Cilegon I. Jurnal Semarak, 2(3), 1-9. 